\title{
- La influencia del arte sasánida en la decoración arqui- tectónica 'abbāssí: de la fragmentación de la trompa de esquina a la creación de un sistema de decoración tridimensional
}

\author{
Alicia Carrillo Calderero \\ Universidad de Córdoba
}

\section{RESUMEN}

La arquitectura islámica presenta un mecanismo de decoración tridimensional que conocemos como muqarnas o mocárabes. Un sistema novedoso creado en el Próximo Oriente entre los siglos VIII y X a partir de la fragmentación de la trompa de esquina, y que en el siglo XI se extendió por toda la geografía del Islam. Sin embargo, la historiografía no se ha detenido especialmente en el origen formal de este elemento y por ello, este estudio pretende demostrar la importancia que tuvo el arte sasánida en la concepción estética de los muqarnas.

PALABRAS CLAVE: arquitectura islámica/ trompas tripartita/ mocárabesmuqarnas/ Sasánidas/ Califato 'abbāsí.

The influence of Sassanid art on the Abbasid architectural decoration: from the fragmentation of the squinche to the creation of a three-dimensional decoration system

\section{ABSTRACT}

Islamic architecture presents a three-dimensional decoration system known as muqarnas. An original system created in the Near East between the 8th and the 10th centuries due to the fragmentation of the squinche, but it was in the 11th century when it turned into a basic element, not only all along the Islamic territory but also in the Islamic vocabulary. However, the origin and shape of muqarnas has not been thoroughly considered by Historiography. This research tries to prove the importance of Sasanian Art in the aesthetics creation of muqarnas

KEY WORDS: Islamic architecture/ tripartite squinches/ muqarnas/ Sasanian and Abbasid caliphate.

\section{INTRODUCCIÓN:}

En el arte islámico ha existido siempre un cierto "horror vacui", entendido como una tendencia materializada en la decoración casi abusiva del interior de los edificios, que cubre prácticamente la totalidad de las superficies. Esta tendencia se explica, según señaló hace algunos años Richard Ettinghausen, por la preferencia que tiene el musulmán por los espacios totalmente cubiertos por decoración, en detrimento de las superficies desprovistas de ornamento que originan en él un sentimiento de vacío e inseguridad ${ }^{1}$.

* CARRILLO CALDERERO, Alicia: "La influencia del arte sasánida en la decoración arquitectónica 'abbāssí: de la fragmentación de la trompa de esquina a la creación de un sistema de decoración tridimensional”, en Boletín de Arte $n^{\circ}$ 32-33, Departamento de Historia del Arte, Universidad de Málaga, 2011-2012, págs. 91-115. Fecha de recepción: Marzo de 2011. 
Para entender esta cuestión, es necesario que nos remontemos al año 0/622 cuando comienza la expansión territorial del Islam. Aquellos hombres del desierto desprovistos de comodidades y lujo, alentados por el grito de la Ŷihād islámica, partieron desde los inhóspitos desiertos árabes y sin duda, debieron sentirse atraídos y maravillados cuando al paso de sus conquistas, contemplaron las edificaciones romanas y bizantinas que ponían ante sus ojos la magnificencia decorativa de los mosaicos, capiteles y pinturas. Pero también, la grandiosidad del Imperio Persa se postró ante sus pies con sus grandes complejos palatinos, recuerdo de la fuerza y del poder de aquellos aguerridos emperadores. La estabilidad arquitectónica de los edificios sobrepasó los límites de aquella ideología nómada, una estabilidad física aderezada con grandes programas decorativos que embellecían los muros y reflejaban lujo y exquisitez.

Asentados los musulmanes en el poder, no dudaron en aplicar estos motivos y sistemas ornamentales a sus construcciones y así, aquellos Omeyas de Oriente emplearon magníficos mosaicos en la decoración de sus dos grandes obras: la Cúpula de la Roca y la Mezquita de Damasco. Sin embargo, el arte de los 'Abbāssíes enriquece su vocabulario artístico con otras formas y elementos cuyo origen oriental confiere a sus manifestaciones un cierto aire de abstracción geométrica. La causa de este cambio estético debemos buscarla en el traslado de la capital del Imperio, de Damasco a Bagdad. Damasco, destacada ciudad de la antigüedad clásica, era un centro artístico con una herencia y un legado cultural que los califas omeyas quisieron imitar y trasladar a sus creaciones, como si con ello quisieran investirse de la dignidad de los emperadores romanos. Sin embargo, la antigua Bagdad fue fundada por el Califa 'abbāssí al-Manșūr en el año 144/762, en los terrenos de la antigua Persia, territorio de otrora poderosos emperadores pero también de una arquitectura y una tradición artística diferentes, caracterizadas por una decoración arquitectónica consistente en relieves ornamentales y en fachadas con entrantes y salientes, siendo precisamente esta última una de las principales características de la arquitectura de los Sasánidas, último de los pueblos persas. La unión de ambas tradiciones generó un espectro ornamental que sufrió la consecuente evolución y enriquecimiento con el paso de los siglos pero siempre rico y variado, a pesar de algún período de escasez decorativa como la primera época del arte almohade.

Es precisamente esta tendencia decorativa del arte islámico, constante y variada, la que haga que la decoración se convierta en su signo de identidad², destacando entre el amplio repertorio ornamental que ofrece, un sistema de decoración tridimensional, los muqarnas o mocárabes ${ }^{3}$, cuya formación y desarrollo corresponden

1 FRISHMAN, M; KHAN, H., The Mosque. History, architectural development and regional diversity. London, Thames and Hudson, 1994, p. 67.

2 MORALES, A. J., Historia del Arte islámico. Barcelona, Planeta, 1995, p. 69.

3 En realidad, el término "mocárabe" procede de la castellanización del vocablo árabe "muqarbas" cuyo significado es "adorno de talla". El término "muqarbas" aparece asociado al de "muqarnas", también de origen árabe, y aunque son muy pocos los autores que diferencian entre un término u otro, la Enciclopedia Islámica, tanto en la versión inglesa como en la francesa, contempla ambos vocablos distinguiendo el uso de "muqarbas" para los ejemplos localizados en Occidente y "muqarnas" para los de Oriente; en BOSWORTH, C. E., "Mukarbas" y BEHRENS-ABOUSEIF, D., "Muḳarnas", en AA.VV. Encyclopedie de L'Islam. Tomo VII, Leiden, E. J. Brill, 1993, págs. 500 y 501; FERNÁNDEZ PUERTAS, A., "Mukarbas" y BEHRENS-ABOUSEIF, D., "Mukarnas", 
al arte islámico, adoptándolo el arte mudéjar en muchas de sus manifestaciones. Este sistema decorativo que se creó en el Próximo Oriente entre los siglos VIII y X a partir de la fragmentación de la trompa de esquina, tuvo un éxito enorme desde el siglo XI, extendiéndose por toda la geografía del Islam hasta convertirse en parte fundamental del vocabulario del arte islámico. La utilización de estas estructuras decorativas representa en la decoración musulmana un papel muy importante por su enorme atractivo estético y por su ductilidad para adaptarse fácilmente a cualquier superficie arquitectónica. Sin embargo y a pesar de su consabida utilización y amplio desarrollo, plantearnos un dónde y un por qué se crearon los muqarnas no es fácil, ya que las investigaciones sobre el tema son en su mayoría bastante superficiales ${ }^{4}$. Algunos autores como Ettinghausen, Grabar, Beylié, Creswell o Al-Tabba se han aventurado en señalar cuatro focos posibles en el origen de estos elementos, localizados tanto en Oriente como en Occidente. Los historiadores que han indicado el Oriente islámico como zona de origen de los muqarnas, han señalado el nordeste de Irán, Iraq y Egipto como lugares pioneros en la utilización de estos elementos pero también se recoge el Norte de África, como lugar gestor de estas formas ornamentales, de una manera paralela al nacimiento oriental y prácticamente en el mismo momento cronológico.

Esta diversidad de opiniones revela que la cuestión del origen geográfico de los muqarnas es muy compleja y que realmente pocos son los historiadores que se han ocupado de profundizar en este tema. Las hipótesis que señalaron en su momento el Norte de África como posible foco creador de los muqarnas, han sido ampliamente revisadas y descartadas. Por ello, opinión generalizada es su filiación oriental, siendo precisamente las teorías que se centran en el nordeste de Irán e Iraq las más documentadas y aceptadas científica y documentalmente, donde podemos encontrar tres edificios muy representativos como son el Mausoleo sāmāní de Bujara (301/914-331/943) en la actual Uzbekistán, las cúpulas suroeste y nordeste (464/1072 y 480/1088) de la Mezquita silŷuquí de Isfahán en Irán y la Tumba del Imān al-Dāwr (477/1085) en Samarra, Iraq.

El problema surge en el momento en que entre estas manifestaciones no se puede establecer una evolución formal si se atiende a su cronología y ni siquiera cuando existe una coexistencia en el tiempo, pues el modelo de muqarnas que se desarrolla en cada uno de estos edificios es diferente. Efectivamente, en Bujara aparecen los primeros indicios de la fragmentación de la trompa de esquina o por lo menos se trata del ejemplo más antiguo conservado. Sin embargo, dos manifestaciones coetáneas en el tiempo como son las cúpulas suroeste y nordeste de la Mezquita de Isfahán y la cúpula del mausoleo del Imān al-Dāwr en Samarra, presentan un concepto formal y espacial de los muqarnas muy diferente. En las cúpulas iraníes de la gran mezquita

en AA.VV. Encyclopaedia of Islam. CD-ROM Edition v.1.1., Leiden, Koninklijke Brill NV, 2001. De otra parte, respecto a la utilización del término árabe en castellano, en la historiografía se emplea el género masculino y el femenino indistintamente, esto es, "los muqarnas" o "las muqarnas".

4 "(...) El origen de las muqarnas o abovedado en estalactita, llamado también en alveolos, elemento esencial, de una forma u otra, en toda la arquitectura islámica 'clásica', nunca se ha establecido”, en HOAG, J. D., Arquitectura islámica. Madrid, Aguilar S.A., 1976, p. 146. 
silŷuquí, los muqarnas se aplican en la zona de transición, continuando de alguna manera con la tendencia iniciada o copiada de algún otro lugar del nordeste iraní, habida cuenta de la existencia del Mausoleo sāmāní de Bujara, que acabamos de mencionar y sobre el que nos detendremos a continuación. La Tumba del Imān al-Dāwr de Samarra, muestra por el contrario, una decoración de celdas de muqarnas que ocupa la totalidad del espacio de la cubierta, traduciéndose sus formas al exterior y constituyéndose un tipo de cúpula que será característico de Iraq y de la Siria ayyūbí.

Abordar esta problemática geográfica respecto al origen de los muqarnas ${ }^{5}$, requiere en primer lugar un estado de la cuestión, que permita dirigir el estudio hacia las teorías más documentadas. Al desentrañar ese estado de la cuestión, llegamos a una conclusión como es la adscripción al Califato 'abbāsí de este nuevo sistema tridimensional. Sin embargo, esta filiación del Califato de los 'Abbāsíes con la creación de los muqarnas, no es nueva sino que ya la propuso Yasser Al-Tabbaa finales de la década de los ochenta ${ }^{6}$. Por ello, partiendo de esta hipótesis ya planteada cabe preguntarnos qué circunstancia motivó o provocó durante el Califato 'abbāsí la renovación de la estética islámica vigente hasta ese momento. La propuesta que hacemos para explicar esta circunstancia es la influencia del arte sasánida en el origen formal de los muqarnas a partir de la fragmentación de la trompa de esquina. Una influencia que indudablemente entendemos está basada en unos condicionantes estéticos y estructurales, como son la articulación de las fachadas en entrantes y salientes y la utilización del arco aquillado, componentes de esa arquitectura persa inmediatamente anterior a la llegada del Islam, la arquitectura sasánida, cuya influencia será notable fundamentalmente a partir del Califato 'abbāsí por el consecuente traslado de la capital de Damasco hacia Bagdad.

2. De LA FRAgmentación dE LA TROMPA dE ESQUINA A LA CREACIÓN DE UN SISTEMA DE DECORACIÓN TRIDIMENSIONAL:

El germen formal de los muqarnas debemos buscarlo como venimos diciendo, en la fragmentación de la trompa de esquina a partir de pequeños nichos cóncavos con forma de arcos apuntados o aquillados. Estas primeras manifestaciones de muqarnas concebidas en las trompas de ángulo, fue el inicio de un mecanismo formal extraordinariamente estético y que dará lugar a todo un sistema de decoración tridimensional, en palabras de Ecochard, esas trompas fragmentadas por pequeños nichos cóncavos eran la "préfigurations de muqarnas"7.

La evolución formal de los muqarnas en las trompas pasó desde el ejemplo más antiguo conservado como es el Mausoleo del príncipe sāmāní Ismā'īl en Bujara

5 CARRILLO CALDERERO, A., "Origen geográfico de los muqarnas: Estado de la cuestión", Al-Mulk. Anuario de Estudios arabistas, II Época, n 5, Córdoba, 2005, págs. 33-48.

6 AL-TABBA, Y. A., "The muqarnas dome: its origin and meaning", Muqarnas. An annual on islamic art and architecture, Vol. III, Leiden, 1985, págs. 61-74.

7 ECOCHARD, M., Filiation de monuments grecs, byzantins et islamiques. París, Geuthner, 1977, p. 65. 
fechado en la primera mitad del siglo X como ya hemos indicado, en el que se observa una primitiva muestra de trompa fragmentada por nichos, hasta las trompas silŷuquíes de la Mezquita de Isfahán, de la segunda mitad del siglo XI, las cuales presentan un tratamiento geométrico y formal mucho más elaborado. En realidad, el concepto podemos interpretarlo formalmente como una multiplicación de la trompa propiamente dicha $^{8}$, que cumple la misma función como zona de transición de la sala a la cúpula pero mucho más decorativa. No hay que olvidar, que el sistema de la trompa de esquina para salvar la transición del cuadrado a la cúpula, ya había sido utilizado en la arquitectura sasánida, romana y bizantina pasando a formar parte, como otros elementos, del vocabulario arquitectónico islámico, empleándose en las primeras construcciones $^{9}$. Por tanto, la novedad no va a estar en la utilización de trompas sino en la elaboración o decoración de las mismas a partir de su propia división o fragmentación. Pues bien, a partir de esta fragmentación de la trompa de esquina en pequeños nichos cóncavos se pasó en el siglo XI a la extracción de los mismos del límite de la trompa para convertirlos en unidades decorativas independientes, dotadas de una composición y construcción geométrica mucho más elaborada que tuvo como resultado el nacimiento de un nuevo sistema tridimensional empleado en la decoración arquitectónica. Este nuevo mecanismo de prismas colgantes que ocultará totalmente la estructura de la trompa de esquina ${ }^{10}$, conocerá diferentes materiales y técnicas de decoración añadida ${ }^{11}$, y su uso se extenderá a partir de este momento, a la totalidad de la cúpula e incluso a otras superficies, como cornisas y capiteles. Fue en el siglo XII cuando la construcción geométrica de los muqarnas se hizo más complicada pudiendo hablar ya no de nichos cóncavos sino de auténticos prismas creados geométricamente, un nuevo sistema más complicado que pasó a al-Andalus y que por ende, adoptó el arte mudéjar ${ }^{12}$.

8 ROSINTAL, J., Pendentifs, Trompen und Stalaktiten. Beiträge zur Kenntnig der islamischen architektur. Leipzig, J.C. Hinrichs'sche Buchhandlung, 1912, p. 51.

9 CRESWELL, K.A.C., Compendio de Arquitectura paleoislámica. Cádiz, Publicaciones Universidad de Sevilla, 1979, p. 74.

10 AHLENSTIEL-ENGEL, E. (1927), Arte árabe. Barcelona, Labor S.A., 1932, p. 129. [A propósito de los muqarnas] “(...) Característico del poco sentido arquitectónico de los árabes fue el que las aplicaran en pechinas y cúpulas. No perturbaba al arquitecto árabe en manera alguna el cubrir con ellas las puras líneas de una cúpula y destruir así su efecto".

11 En Irán y la actual Uzbekistán, se utilizó preferentemente el ladrillo para la construcción de muqarnas por lo menos hasta el siglo XIII pues con los mongoles y de acuerdo con una evidente evolución y perfeccionamiento de esta técnica decorativa, el material utilizado fue el yeso. En Siria y Egipto por el contrario, se abogó por la utilización de la piedra como material constructivo de estos elementos, mientras que el Magreb y en alAndalus se optó por el yeso e incluso la madera. Respecto a las técnicas decorativas añadidas, nos referimos indudablemente a la policromía que suele acompañar los muqarnas, generalmente de fuertes y vivos colores, reproduciendo multitud de motivos.

12 Para el estudio de la construcción y composición geométrica de los muqarnas o mocárabes hay pocos pero interesantes estudios, siendo sin duda uno de los más destacados el que el maestro de alarifes sevillano Diego López de Arenas hizo en el siglo XVII y que publicó en una obra teórica titulada Breve compendio de la carpintería de lo blanco y Tratado de alarifes. En este obra, se recoge una construcción de mocárabes cuya composición geométrica sería fundamentalmente la aplicada y utilizada en el arte nazarí (siglos XIII-XV) y no anterior pero en cualquier caso, se trata de un estudio de sumo interés para conocer los principios básicos empleados en la construcción de estos elementos. Para el estudio de esta obra, es muy interesante la edición facsímil anotada y con estudio preliminar de Manuel Gómez Moreno, publicada en Madrid por el Instituto de Valencia de Don Juan, en el año1966, y también la edición anotada con estudio preliminar de $\mathrm{M}^{a}$ Ángeles 
Sin embargo y a pesar de la lógica evolución de este sistema, no es posible establecer en qué lugar se fragmentó por primera vez la trompa de esquina pues el desconocimiento existente sobre manifestaciones tempranas de muqarnas, realizadas a partir de la fragmentación de la trompa y fechadas en el siglo X es notable a causa de los escasos ejemplos que de esta época han llegado hasta nuestros días, localizados en el nordeste iraní. Esta circunstancia motivó que durante mucho tiempo se hablase del nordeste de Irán como foco creador de los muqarnas. Sin embargo, en Iraq se conservan manifestaciones fechadas en la primera mitad del siglo XI, en las que se observa una utilización de muqarnas mucho más elaborada y que trasciende más allá del espacio de la trompa, lo que conduce inequívocamente a replantearnos esta cuestión.

\section{1.- Origen geográfico de los mugarnas: Estado de la cuestión.}

A priori no cabe duda de que la línea evolutiva en la formación de los muqarnas arranca desde la fragmentación de la trompa de esquina hasta la creación de prismas dotados de un alto componente geométrico, que de manera aislada al soporte arquitectónico se convierten en un sistema ornamental recurrente en la arquitectura islámica. Sin embargo, el dónde y el porqué surge por primera vez este intento por decorar la trompa de esquina son interrogantes que sin duda, merecen una respuesta pero que previamente requieren un breve recorrido por lo que se ha investigado hasta ahora.

\subsubsection{EL NORDESTE DE IRÁN: SEGMENTACIÓN DE LA TROMPA DE ESQUINA COMO ORIGEN} CONSTRUCTIVO DE LOS MUQARNAS.

El estudio que proponemos comienza por analizar el foco geográfico en el que tuvo lugar por primera vez la fragmentación formal de la trompa de esquina y para ello, es necesario hablar del nordeste iraní por ser el lugar en el que se localizan las manifestaciones más antiguas conservadas. El Mausoleo del príncipe sāmāní Ismāīil en Bujara -Uzbekistán- se construyó entre los años 301/914 y 331/943 según los autores ${ }^{13}$, como un edificio de planta cuadrada cubierto por una cúpula central y cuatro cupulitas en las esquinas ${ }^{14}$. La cúpula apoya sobre trompas que convierten el espacio cuadrado en un octógono y en ellas, se puede apreciar una composición formada por medio de dos nichos cóncavos separados por una especie de nervio. Esta fragmentación de la trompa de esquina responde a un deseo ornamental de la construcción sāmāní que contribuye a enriquecer la zona de transición [1].

Toajas Roger, publicada también en Madrid por la editorial El Visor Libros, en 1997.

13 ETTINGHAUSEN, R.; GRABAR, O., Arte y Arquitectura del Islam. 650-1250. Madrid, Cátedra, 2000, p. 236. Sin embargo, otros autores proponen la construcción del edificio con anterioridad a la muerte de Ismail en el año 293/907, en POPE, A.U., Persian architecture. Londres, Thames and Hudson, 1965, p. 81.

14 Para un estudio más pormenorizado sobre este edificio, consultar: REMPEL, L., "The mausoleum of Isma'il the Samanid", en Bulletin of the American Institute for Persian Art, vol. 4, Germantown, 1935. 


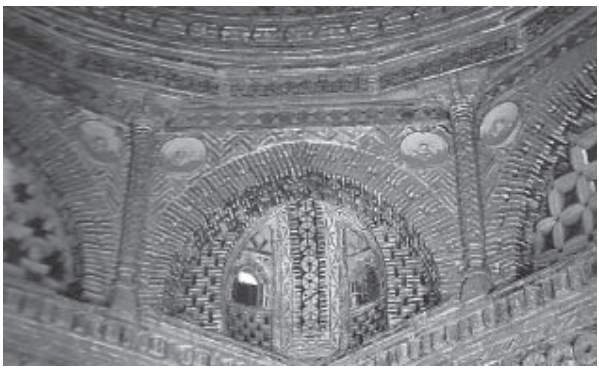

1. Interior zona de transición del Mausoleo del príncipe sāmāní Ismầ̄ en Bujara -Uzbekistán- (301/914 y 331/943). A.A.V.V. El Islam. Arte y Arquitectura. Ed. Könemann. Colonia, 2000 [de la edición española, Barcelona, 2001]. p. 115
2. Dibujo de la zona de transición de la Tumba de Arab Ata en Tim-Uzbekistán(366/977-367/978).

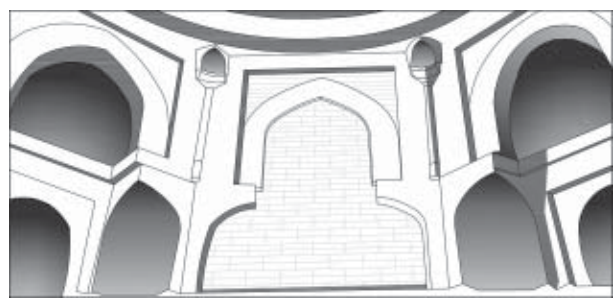

Muy próxima a Bujara se encuentra la localidad de Tim -Uzbekistán- donde se erige la Tumba de Arab Ata fechada entre los años 366/977 y 367/978. La configuración es muy similar al Mausoleo de Bujara, su planta es cuadrada y se cubre con cúpula que apoya sobre trompas de muqarnas. Respecto al sistema empleado en Bujara, la zona de transición del cuadrado a la cúpula en Tim está más evolucionada o si se quiere es más decorativa, pues en este caso son tres los elementos que se emplean en la trompa. Estos tres elementos se encuentran enmarcados en la parte superior por un nicho de sección apuntada que a su vez aparece rodeado por una especie de alfiz, configurándose una zona de transición a la cúpula muy dinámica [2].

El sistema se traslada hacia otros puntos de Irán y evoluciona progresivamente a partir ya del siglo XI momento en el que se generaliza. Interesante es el caso de la Tumba del Imān Duvazde en Yazd, localidad situada en el centro de Irán, construida hacia el año 427/1037 y cuya cúpula apoya sobre unas trompas constituidas por nichos de muqarnas de una manera mucho más evolucionada que las trompas de la Tumba de Tim. De hecho, para algunos autores esta bóveda iraní se considera la cúpula más antigua de muqarnas conservada ${ }^{15}$. Resultaría de lo más esclarecedor suponer una influencia de Tim sobre Yazd, ésta última con un tratamiento más evolucionado, menos pesado y jugando más con los volúmenes que influiría directamente sobre las cúpulas silŷuquíes de la Mezquita de Isfahán.

En efecto, será esencialmente bajo la dinastía de los turcos Silŷuquíes (429/1038$551 / 1157$ ) cuando asistamos a un uso mucho más generalizado de los muqarnas, utilizados

15 ETTINGHAUSEN; GRABAR, op. cit. p. 313. 


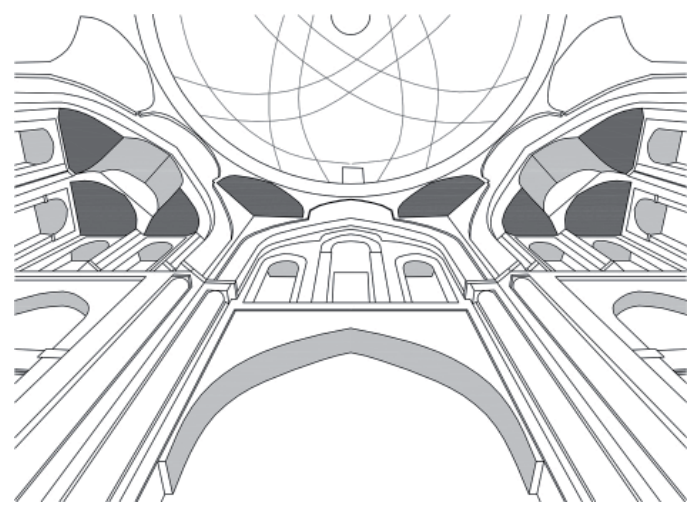

3. Mezquita de Isfahan -Irán(480/1088): dibujo de la cúpula nordeste.

no sólo en la ornamentación de la trompa de esquina sino también en otros elementos arquitectónicos como las cornisas. Sirva como ejemplo de lo primero, las cúpulas silŷuquíes suroeste y nordeste de 464/1072 y 480/1088 respectivamente, de la Mezquita de Isfahán en Irán ${ }^{16}$. En ellas, se observa la evolución de la trompa que desde Tim y pasando por Yazd llega hasta Isfahán, donde la composición tiende hacia la tridimensionalidad. La trompa está formada por cuatro nichos, el central actúa como un segmento de bóveda de cañón y apoya sobre una trompa simple, los laterales mantienen la forma de nicho cóncavo apuntado, habitual en el nordeste iraní. Sobre estas trompas de muqarnas, dieciséis trompas simples también dan paso a la base circular de la cúpula hemi-esférica, esta última solución estructural ha sido denominada como "red de pechinas"17 [3], y su utilización contribuye a enriquecer notablemente la zona de transición.

Llegados a este punto, observamos perfectamente la tendencia existente en Irán respecto a la fragmentación de la trompa de esquina, contribuyendo a un enriquecimiento estético y formal de la zona de transición. Dicha tendencia comenzó con una fragmentación de la trompa muy simple, básicamente supuso una división de la trompa en pequeños nichos cóncavos, como se ha podido comprobar. La expansión de esta nueva técnica desde el nordeste hacia el centro de Irán, tuvo como consecuencia la lógica evolución de los elementos utilizados y así, la fragmentada trompa de esquina fue desarrollándose y complicándose hasta desembocar en construcciones más elaboradas como las de Yazd, Isfahán y las de la Mezquita de Ardestán [4], fechada en un momento posterior, entre los siglos XI y XII y en la que se puede apreciar la influencia de las cúpulas silŷuquíes de Isfahán pues mantiene la misma compartimentación de las trompas e incluso la misma galería formada por esa "red de pechinas" ${ }^{18}$. Analizando detenidamente las manifestaciones orientales contemporáneas

16 Más datos sobre la Mezquita de Isfahan en GRABAR, O., The great mosque of Isfahan. London, I. B. Tauris, 1990.

17 ETTINGHAUSEN; GRABAR, op. cit p. 313.

18 FRISHMAN; KHAN, op. cit. p. 123. La influencia de las cúpulas de Isfahán se dejó sentir en pequeñas mezquitas como la de Ardestán, Zavara o Basiyan, en las cuales obviamente el diseño de trompas de muqar- 
a Isfahán en otros países e incluso en otros puntos de Irán, queda de manifiesto que este renovado sistema de trompas no tuvo continuidad más allá de pequeños edificios próximos a la capital silŷuquí, quizá "porque su complejidad no era equiparable a la tecnología del momento"19.

Partiendodeestafragmentación de la trompa de esquina, a partir del sigloXI la utilización de muqarnas como recurso ornamental de la arquitectura islámica se convirtió en una tendencia al alza, traspasando los límites físicos de la zona de transición y decorando la totalidad de la cúpula, amén de otras superficies como cornisas -Gumbad-i 'Alī en Abarquh (Irán) 447/1056²0-, capiteles o nichos. Se desconoce en qué momento la composición de estos elementos evolucionó de forma notable, hasta el punto de convertirse en estructuras geométricas colgantes, totalmente independientes del soporte arquitectónico que se yuxtaponen hasta cubrir el espacio requerido. Al respecto, es interesante destacar el hallazgo de restos de muqarnas en las excavaciones que el Museo Metropolitano de Nueva York llevó a cabo en Nishapur -Irán-, en la década de los años cuarenta del siglo XX. En dichas excavaciones se encontraron los restos de un palacio fechado en el siglo $\mathrm{X}, \mathrm{y}$ entre los fragmentos materiales que pertenecieron a este edificio, aparecieron unos restos realizados en estuco con forma de pequeños nichos cóncavos y decorados con pinturas que debieron formar parte del ornamento de una cúpula ${ }^{21}$.

Estos fragmentos hallados en Nishapur, constituyen un punto de inflexión muy interesante porque plantea dos grandes interrogantes. El primero conduce a reflexionar sobre la fecha propuesta para estos fragmentos pues el hecho de que sean piezas sueltas realizadas en yeso colocadas a posteriori en la cúpula, propone en comparación con manifestaciones posteriores una cronología mucho más avanzada que el siglo $\mathrm{X}$.

nas propio de la mezquita de la capital, se muestra más sencillo y menos complicado.

19 ETTINGHAUSEN; GRABAR, op. cit p. 315.

20 HOAG, op. cit. p. 146: “(...) El Gunbad-i-Ali de Abarquh en Persia central, del 1056, presenta el primer ejemplo de cornisa exterior con muqarnas".

21 ETTINGHAUSEN; GRABAR, op. cit. p. 242. La cronología que se plantea para estos restos de muqarnas es el siglo X e incluso el siglo IX, en GRABAR, O., La formación del arte islámico. Madrid, Cátedra, 1986, p. 206. 
En segundo lugar, aceptando que los restos de muqarnas de Nishapur se realizaran en el siglo $\mathrm{X}$ habría que plantearse un primitivo uso como elementos sueltos en yeso que conocieron un desarrollo paralelo en ladrillo y formando parte de las trompas. Esta opción es poco probable pues en los dos mausoleos comentados, Bujara y Tim, se observa claramente la torpeza arquitectónica respecto al uso de este elemento, lo que conduce a una inequívoca primitiva utilización como fragmentación de las trompas de esquina. Por ello, entendemos que los fragmentos de muqarnas hallados en Nishapur deben fecharse a partir del siglo XI, en correspondencia con otros ejemplos conservados en la Kal'a de los Banū Ḥammād en Argelia, con los restos de muqarnas hallados en el Ḥammām de Abū'l-Su'ud en El Cairo e incluso con los mocárabes encontrados en el Convento de Santa Clara de Murcia y pertenecientes a un palacio anterior fechado en época mardanisí (siglo XII) ${ }^{22}$. Si bien es cierto que las pinturas de Nishapur denotan un momento precedente o menos evolucionado a las que decoran los ejemplos cairotas y murcianos mencionados, defendemos que su fecha de realización debe ser posterior al siglo X, como hasta ahora se había propuesto.

En cualquier caso, y aceptando una cronología posterior para los fragmentos de muqarnas encontrados en Nishapur, parece evidente la filiación existente entre la fragmentación de la trompa de esquina como su origen constructivo, y un uso posterior de este recurso arquitectónico más decorativo, basado en la introducción de las celdas de muqarnas independientes de la estructura de la trompa y realizadas fundamentalmente en yeso, consecuencia de la propia evolución de esta técnica.

Un origen estructural de los muqarnas reconocible en el nordeste iraní pero que también se puede observar en Egipto, concretamente en una serie de mausoleos conservados en la necrópolis de Asuán y fechados entre finales del siglo $\mathrm{X}$ y principios del $\mathrm{XI}$.

\subsubsection{LOS MUQARNAS EN EGIPTO: REVISIÓN DE UNA HIPÓTESIS.}

Tradicionalmente y de acuerdo con las investigaciones de Creswell, se ha contemplado la teoría de que los muqarnas pudieron tener en Egipto un nacimiento coetáneo al del nordeste iraní, consecuencia de las tradiciones que existían en el país. En este sentido, Creswell apuntó la posibilidad de que en Egipto tuviese lugar un desarrollo de los muqarnas paralelo al del nordeste iraní2 ${ }^{23}$, partiendo también de la fragmentación de la trompa de esquina y basándose en la existencia de ejemplos fechados en los siglos XI y XII ${ }^{24}$, localizados en la ciudad de El Cairo y en la

22 Entre otros estudios de Julio Navarro Palazón podemos destacar los siguientes: NAVARRO PALAZÓN, J., "La Dâr aṣ-Ṣugrā de Murcia. Un palacio andalusí del siglo XII", en AA.VV. Colloque international d'archéologie islamique. Le Caire, 3-7 février 1993, Le Caire, Institut français d'archéologie orientale (IFAO). Textes árabes et études islamiques, 1998 y NAVARRO PALAZÓN, J.; JIMÉNEZ CASTILLO, P., "Arquitectura mardanisí", en LÓPEZ GUZMÁN, R. (Coord.), La arquitectura del Islam occidental. Barcelona, El Legado Andalusí, Lunwerg Editores y Collection UNESCO, 1995, p. 125.

23 CRESWELL, K. A. C., The muslim architecture of Egypt. London-Oxford, 1952.

24 BLOOM, J., "The introduction of the muqarnas into Egypt", Muqarnas. An annual on islamic art and archi- 
5. Dibujodelazonadetransición
de uno de los mausoleos de la
necrópolis de Asuán -Egipto-
(siglos XI y XII).

necrópolis de Asuán. En estos ejemplos, se observa que la utilización de muqarnas no responde a meros balbuceos arquitectónicos sino que se trata de una técnica constructiva y ornamental plenamente desarrollada e integrada en la arquitectura. Una circunstancia que para Creswell fue determinante, planteando esta hipótesis que en su momento compartieron otros autore ${ }^{25}$, una posibilidad que tradicionalmente ha sido aceptada entendemos que ante el vacío bibliográfico y documental existente al respecto y que sin embargo, hoy está totalmente descartada. En efecto, en algunos mausoleos localizados en la necrópolis de Asuán y fechados entre finales del siglo $X$ y comienzos del siglo XI se puede observar un sistema muy similar al que hemos visto en la Tumba de Arab Ata en Tim -Uzbekistán- del siglo $X^{26}$, de trompa dividida en cuatro nichos cóncavos de sección apuntada [5].

En el caso de los ejemplos tempranos de muqarnas documentados en El Cairo, aparecieron en la antigua Fustat, en las ruinas del Hammām de Abū'l-Su'ud, unos restos de celdas o nichos muy similares a los ejemplos de Nishapur, realizados en estuco y decorados con pinturas que se han relacionado con la decoración abbāssí de Samarra, fechándose por tanto entre los siglos IX y $X^{27}$. El hallazgo de estos restos de muqarnas fechados en principio con anterioridad a la llegada de los Fāțimíes, supuso un importante aliciente para respaldar la presencia y utilización de muqarnas en Egipto de forma paralela y prácticamente en el mismo momento que en el nordeste iraní. Sin embargo, al igual que con los estucos de Nishapur debemos plantear una

tecture, Vol. V, Leiden, 1988, págs. 21-28. Unas cuestiones que posteriormente tratará en otro estudio más reciente: BLOOM, J., Arts of victorious: Islamic art and architecture in Fatimid North Africa and Egypt. New Haven, Yale University Press, 2007, págs.. 132 y ss.

25 ETTINGHAUSEN; GRABAR, op. cit p. 364.

26 Parece más que probable en estos mausoleos de Asuán la influencia de la arquitectura iraní pues no sólo aparece la trompa tripartita sino que en otros mausoleos, los catalogados por Monneret de Villard con los números 17 y 54, la trompa se ha resuelto como semicírculo concéntricos de ladrillo en forma de semi-cono como las trompas sasánidas, en MONNERET DE VILLARD, U., La necropoli musulmana di Aswan. Le Caire, Ed. L'Institut Français d'Archéologie orientale, 1930, págs. 50 y 51.

27 BEHRENS-ABOUSEIF, Encyclopedie de L'Islam...op. cit. p. 501. Unos fragmentos, conservados actualmente en el Museo islámico de El Cairo y que presentan pinturas tales como una bailarina y un joven sentado con una copa en la mano. Se cree que formaban parte de una cúpula quizá como elementos de transición. 


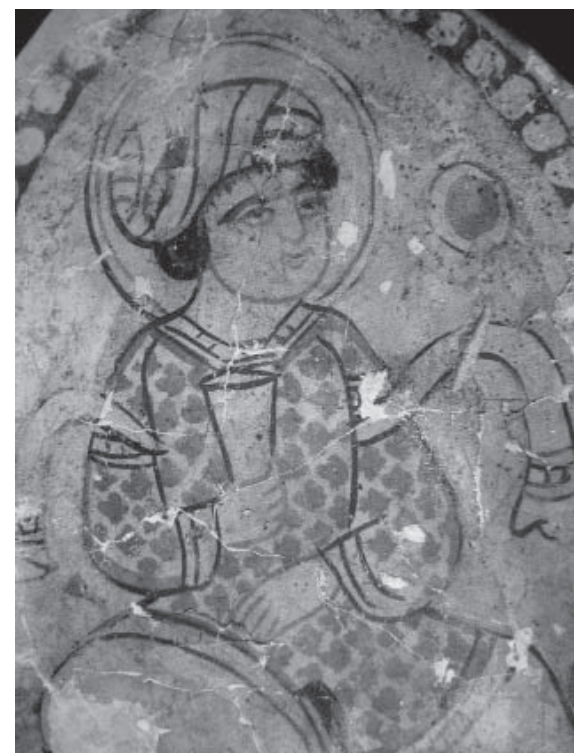

6. Celda procedente del Hammām de Abü'lSu'ud en Fustat (El Cairo) -Egipto- (¿siglos IX-X?). (AA.VV., Le Caire. Paris, Citadelles \& Mazenod. 2000, p. 132). cronología posterior a la sugerida, defendiendo la misma secuencia constructiva de lo estructural de la trompa a lo meramente decorativo de las celdas de estuco [6]. Igualmente, queremos poner de manifiesto las evidentes similitudes que se observan si analizamos detenidamente las pinturas que decoran estas celdas, con la decoración de mocárabes de la Capilla Palatina de Palermo e incluso con los mocárabes hallados en Murcia, anteriormente mencionados, lo cual permite configurar todo un "mar" de influencias y relaciones entre Egipto, la corte normanda de Sicilia y el reino mardanisí, que nos lleva a plantearnos muchas cuestiones que entendemos, no tienen cabida en este estudio sino en otro diferente. A tenor de lo expuesto, sería determinante por tanto un profundo estudio no sólo de las piezas encontradas sino también del espacio en ruinas del Ḥammām

para poder determinar posibles intervenciones posteriores.

A partir del siglo XI, con la dinastía de los Fāțimíes la técnica de los muqarnas está perfectamente consolidada y formando parte del vocabulario arquitectónico del momento, extendiéndose su utilización no sólo en las trompas, como se ha podido comprobar en la Necrópolis de Asuán, sino que igualmente aparecen ponderando elementos arquitectónicos como un nicho, una ventana o la cornisa de un alminar, abandonando su función arquitectónica original. Uno de los ejemplos más interesantes es el alminar de la Mezquita de Badr al-Ŷamālī-conocida como de al-Ŷyyūshī- fechado en el año 477/1085 gracias a una inscripción y en el que se observa el empleo de muqarnas en la cornisa que separa el primer cuerpo del segundo ${ }^{28}$ [7]. Del mismo momento cronológico, sobresale una ventana adintelada con decoración en la parte superior de dos estratos de muqarnas, y localizada en el lienzo norte de la muralla que se conserva en El Cairo, vestigio de la cerca amurallada mandada construir por el mismo visir, Badr al-Ŷamālī, a partir del año 479/1087.

Si hacemos una reflexión de lo hasta aquí expuesto vemos que entre las trompas tripartitas de los mausoleos de Asuán y los últimos ejemplos comentados,

28 CRESWELL, The muslim...op. cit. p. 159: “(...) This is the earliest existing example of a stalactite cornice in Egypt". 
existe una evolución y un cambio de concepto en la utilización de la técnica de los muqarnas. No cabe duda de la relación existente entre los primeros ejemplos con los modelos conservados en el nordeste de Irán y sin embargo, no ocurre lo mismo con respecto a los modelos cairotas del siglo $\mathrm{XI}$, habida cuenta del material constructivo empleado, pues los muqarnas que Badr alŶamālī introdujo en El Cairo además de que tienen una configuración diferente, están realizados en piedra mientras que las manifestaciones silŷuquíes de Irán son de ladrillo. Para Creswell, la técnica de los muqarnas perfectamente asentada en el sistema constructivo del Egipto del siglo XI, pudo ser consecuencia de la evolución que sufren las formas como resultado de tradiciones artísticas anteriores ${ }^{29}$. En el caso de la trompa tripartita de nichos cóncavos empleada en Asuán

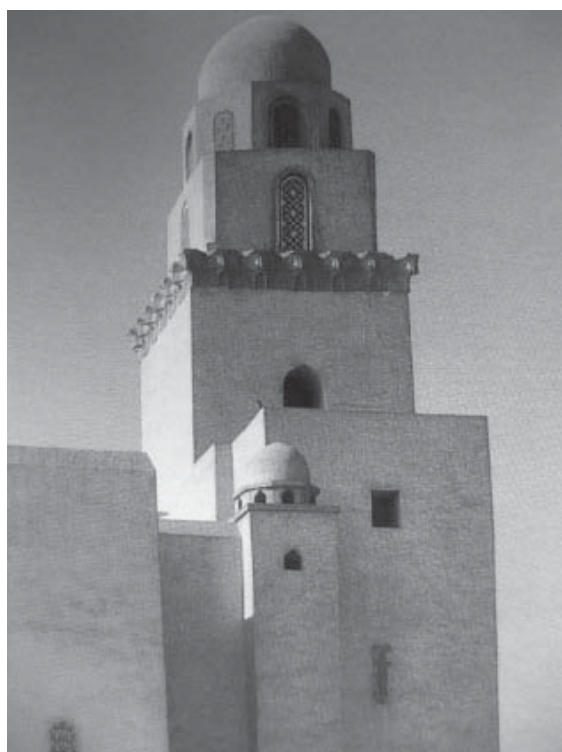

7. Alminar de la Mezquita de al-ŶYuūshī en El Cairo -Egipto- (477/1085). (AA.VV., Le Caire. Paris, Citadelles \& Mazenod. 2000, p. 104). y por tanto primera manifestación de muqarnas en Egipto, Creswell propuso una influencia procedente del Norte de África, a través de la relación existente con la arquitectura copta del momento, sin embargo no especificó de dónde tomaron los Coptos la idea de trompa tripartita ${ }^{30}$.

En este sentido y en contrapartida a las hipótesis de Creswell, habría que plantear dos momentos diferentes en el desarrollo de los muqarnas en Egipto. Un primer momento que coincide con esas primeras manifestaciones en las que los muqarnas son elementos constructivos -trompas de los mausoleos de Asuán- y una segunda fase, desarrollada a partir del año 477/1085, en la que los muqarnas aparecen integrados en el repertorio ornamental de la arquitectura egipcia. Esta fase coincide con el cambio que se desarrolla en Egipto como consecuencia del trabajo de los maestros armenios que acompañaron al general Badr al-Ŷamālī , ya hemos visto como en el segundo recinto murado de El Cairo y en el alminar de la Mezquita de al-Ŷuyūshī, los muqarnas ornamentales aparecen de una manera balbuceante pero con un sentido diferente al planteado en las trompas de Asuán. En la misma línea, hay que destacar que si bien se utiliza la técnica de muqarnas a partir del siglo $\mathrm{XI}$, esto no supone la

30 Idem. p. 232. Basándose en la Iglesia copta de Abu'l-Sayfayn en el viejo Cairo. 
plena aceptación o dominio de este mecanismo en todos los espacios arquitectónicos pues en la Mezquita de al-Ŷuyūshī, los muqarnas se emplean en el alminar pero no en la cúpula situada en el vestíbulo del mihrab y construida en los mismos años ${ }^{31}$.

Todo ello conduce a pensar que en el caso de Egipto podría existir una influencia procedente de otro lugar pues, una invención de los muqarnas paralela a la iraní cuyo resultado sea el desarrollo de un mismo elemento, no puede considerarse como una teoría aceptable. No sería arriesgado proponer, como ya hizo hace unos años el profesor Bloom, una vinculación con las cúpulas sirias, iraquíes o iraníes en un momento muy temprano -siglo XI- a través de las rutas de los mercaderes y peregrinos egipcios que iban hacia la Meca. En este sentido, interesantes son las descripciones de algunos viajeros de la época pues gracias a ellos es posible conocer las rutas comerciales y de peregrinación que cruzaban Egipto en estos momentos. En estas descripciones se deduce el manifiesto desarrollo económico que adquirieron localidades como Asuán, Aydhab o Qus, por ser paso obligado de los mercaderes y peregrinos de Egipto y del Magreb hacia La Meca y viceversa, conocedores y transmisores de lo que habían visto a lo largo de su recorrido ${ }^{32}$. Es probable que el contacto se estableciera primero en Asuán, y desde aquí la técnica llegara hasta la misma capital del Califato fātimí, estableciéndose dificultades lógicas de construcción y ubicación del nuevo mecanismo ornamental pues los artistas egipcios hubieron de adaptarse al empleo de un nuevo elemento ${ }^{33}$, de hecho las trompas de muqarnas presentes en Asuán, no están enmarcadas por ese gran arco como en las manifestaciones iraníes comentadas. Por su parte, la presencia de muqarnas en la capital y más concretamente en las obras patrocinadas por Badr al-Ŷamālī, guarda relación directa con Siria pues anteriormente, el propio Badr al-Ŷamālī había sido gobernador en Damasco ${ }^{34}$.

\subsubsection{Norte de África: los estucos de la Kal’a de los Banū Hammāo.}

A principios del siglo XX Beyliè dirigió unas excavaciones en la Ḳal'a de los Banū Hammād ${ }^{35}$, emplazada en el este de Argelia, y en ellas se hallaron restos de celdas de

31 ETTINGHAUSEN; GRABAR, op. cit. p. 200: "(...) se trata de un tambor octogonal con ocho ventanas que se eleva sobre trompas clásicas".

32 BLOOM, "The introduction...op. cit. p. 26 y 27. Como el persa Nāṣir-i Khustaw (siglo XI) y el andalusí lbn Jubayr al-Kinānī (siglos XII-XIII). El viajero andalusí hace una valiosa descripción de la Masjid al-Harām de la Meca -santuario de la Kaaba- donde destaca la presencia de una puerta la Bab Ibrahim, anexa al santuario propiamente dicho, que tenía una gran cúpula sobre la puerta de entrada cubierta interiormente por un trabajo de estuco o escayola. Ibn Jubayr utiliza para describir esa decoración de la puerta de la Meca el término de qarnasi. Al respecto es muy interesante el estudio de Carol Hillenbrand titulado The Crusades. Islamic perspectives y publicado por Edinburgh University Press en el año 2000.

33 Idem. p. 27. El alto Egipto debió ser la primera zona que recibió esa influencia de las cúpulas de la Meca, Medina y de aquellas zonas visitadas por mercaderes y peregrinos al otro lado del Mar Rojo.

34 Hay que tener en cuenta que el alminar de la gran Mezquita de Aleppo (Siria) tan sólo cinco años posterior al de al-Ŷuyūshī también presenta cornisas de muqarnas. Sobre la figura de Badr al-Ŷamālī, véase: AL-IMAD, L. S., The Fatimid vizierate: 969-1172. Berlin, Klaus Schwarz, 1990, págs. 98 y ss.

35 MARÇAIS, G., "Fatimid art", en Encyclopaedia of Islam...op. cit. En el año 1908 se excavaron el Dar al- 
muqarnas localizados en diferentes núcleos del recinto. En el Kașr alManār (Palacio del Faro o de la Torre) se localizaron los restos de una pequeña semi-cúpula que cubriría un nicho, decorada en origen por muqarnas como ponen de manifiesto las huellas que se conservan en su estructura. Para explicar la función de este elemento, Beyliè se basó en la descripción de los muros exteriores del palacio, destacando la presencia de grandes contrafuertes separados por profundas acanaladuras. En su opinión, estas acanaladuras estaban unidas entre sí por nichos semicirculares rematados en la parte superior por pequeñas cúpulas como la que él encontró, decoradas probablemente con celdas de muqarnas ${ }^{36}$. En el Dār al-Baḥr (Casa del Mar), se localizaron unos fragmentos de cerámica policromados con forma de paralelepípedos acanalados, que fueron calificados por Beyliè como "estalactitas"37, aunque tanto desde el punto de vista formal como constructivo nada tienen que ver con los muqarnas. A pesar de la importancia de estas excavaciones de principios de siglo, mucho más fructíferas fueron las que dirigió Golvin en la década de 1960, en la que se excavó y estudió el Kașr al-Salām (Palacio de la Paz), descubriéndose unos fragmentos de muqarnas decorados con pinturas [8] muy similares a los iraníes de Nishapur que ya hemos comentado ${ }^{38}$.

La cronología propuesta para estos restos de muqarnas es incierta aunque tradicionalmente, se ha considerado la misma fecha que la de fundación del conjunto por Ḥammād ibn Buluggīn I ibn Ziri en el año 397/100739, una adscripción que condujo a algunos historiadores a proponer un origen paralelo de los muqarnas al del nordeste iraní $^{40}$. Sin embargo, ante las invasiones hilalianas, los Hammādíes se retiraron a Bugia

Bahr y el Qasr al-Manar.

36 BEYLIĖ, L., La Kalaa des Beni-Hammad. París, E. Levoux, 1909, p. 39. Un tipo de decoración que él denomina como "ruches d'abeilles" o panales de abejas.

37 Ibid.

38 GOLVIN, L., Recherches Archéologiques a la Qal'a des Banu Hammad. París, G.P. Maisonneuve et Larose, 1965, p. 72.

39 HILL, D.; GOLVIN, L., Islamic architecture in North Africa. London, Faber and Faber, 1976, p. 108.

40 BEYLIE, op. cit. p. 21 e IBN KHALDOUN, Histoire des Berbères et des dynasties musulmanes de l'Afrique 
y la Kal'a fue abandonada hasta el año 482/1090 o principios del siglo XII, momento en el que regresaron y el príncipe hammadí al-Manșūr llevó a cabo una serie de restauraciones y añadidos ${ }^{41}$. El estudio de los restos de muqarnas hallados en el Kașr al-Salām, claramente vinculados con los de Nishapur y con los del Hammām de Abū'lSu'ud en la antigua Fustat, conduce a proponer una cronología posterior a la fecha de fundación del conjunto, es decir, debieron realizarse en la segunda época de la Kal'a ${ }^{42}$.

Esta afirmación se respalda perfectamente por la posterior utilización de muqarnas en el Magreb -manifestaciones almorávides y almohades- en las que no se observa el mismo desarrollo. Si los muqarnas argelinos de la Kal'a se hubiesen realizado a principios del siglo $\mathrm{XI}$, habrían sido el punto de arranque para las posteriores manifestaciones almorávides fechadas en la segunda mitad de ese mismo siglo. Sin embargo, cuando estudiamos detenidamente los muqarnas empleados en la arquitectura almorávide, observamos un tratamiento diferente por lo que no es posible establecer una evolución formal entre las celdas de la Kal'a y las cúpulas de muqarnas almorávides, las cuales deben su influencia a las cúpulas fāțimíes de El Cairo.

Llegados a este punto, sólo cabe proponer una influencia exterior para los muqarnas de la Kal'a a finales del siglo XI o principios del XII, procedente sin duda de Oriente pues las influencias orientales en la Kal'a están perfectamente constatadas y presentes en otras partes del conjunto ${ }^{43}$, es más que probable que se importase el motivo desde Egipto ${ }^{44}$. En cualquier caso, estos hallazgos de la Kal'a de los Banū Ḥammād pueden considerarse como la utilización de muqarnas más antigua del Islam occidental ${ }^{45}$.

\subsubsection{El palacio del Califa 'abbāsí Hārūn ar-Rashīd en la ciudad de RaQQA:} ¿LA PORTADA CON MUQARNAS MÁS ANTIGUA CONSERVADA?

Pocos son los historiadores que sostienen que la existencia de muqarnas en las trompas del iwan sur de la portada principal del Ḳașr al-Banāt en Raqqa pertenecen a la época fundacional de la ciudad -siglo VIII-, cuando el califa 'abbāsí Hārūn ar-Rashīd decidió trasladar la capital del imperio de Bagdad en Iraq a una nueva ciudad fundada por él y llamada Raqqa, localizada en la antigua región de la Ŷazīra -Jazira-, actual Siria ${ }^{46}$. El Califa inició un programa constructivo muy amplio que quiso

septentrionale. Tomo II. [Traduite de l'arabe par Le Baron de Slane, interprète principal de l'armée d'Afrique], Paris, Librairie orientaliste Paul Geuthner, 1925, págs. 51 y 52.

41 BEHRENS-ABOUSEIF, Encyclopedie de L'Islam...op.cit. p. 502 y GRABAR, O., La Alhambra: iconografía, formas y valores. Madrid, Alianza, 2000, p. 176.

42 HOAG, op. cit. p. 77.

43 BEYLIÉ, op. cit. p. 41. Opinión compartida por otros autores, en MARÇAIS, G., El arte musulmán. Madrid, Cátedra. Cuadernos de Arte, 1991, p. 96.

44 GOLVIN, L., "Kal'at Bani Hammad", en Encyclopaedia of Islam... op. cit. Al respecto, es muy interesante la similitud existente entre estos muqarnas y los empleados en el Palacio normando de la Ziza en Palermo, cuyo uso y decoración se debe a los contactos mantenidos con el Egipto fatimí, en GOLVIN, Recherches... op. cit. págs. 125 y 126 .

45 Idem. p. 127: “(...) la Qal'a ait hérité directement de l'Orient un thème architectural que Mahdiya, Tunis, ou Abra eussent ignoré".

46 MEINECKE, M., "From Mschatta to Samarra: the architecture of ar-Raqqa and its decoration", en AA.VV. 
embellecer y adornar con todo tipo de elementos. En efecto, en el interior del iwan sur se emplean muqarnas en las trompas que debieron sostener una cúpula, de la cual desconocemos su decoración pues no se conserva. Hasta ahora esta decoración de muqarnas se había considerado obra del califa Hārūn ar-Rashīd, lo que planteó una fecha muy temprana para la utilización de este recurso ornamental en la arquitectura islámica ${ }^{47}$, con un marcado sentido decorativo ${ }^{48}$. Sin embargo, esta utilización de muqarnas nada tiene que ver con la trompa tripartita de los primeros momentos y que se puede documentar en el nordeste iraní y en Egipto, como ya hemos visto, sino que la forma de las celdas se asemeja de manera asombrosa con la decoración de muqarnas empleada en la propia Siria pero en los siglos XII y XIII.

Llama poderosamente la atención el parecido existente entre el tamaño y la forma de las celdas de muqarnas de Raqqa y los muqarnas empleados en la arquitectura de los Zéngidas (521/1128-5691174) como por ejemplo en el Māristān Nūri de Damasco, primer monumento que Nūr al-Dīn erigió en esta ciudad tras hacer de ella su capital, en el año 548/1154. El iwan de entrada está cubierto por una fantástica bóveda de muqarnas cuyas celdas se asemejan a las de Raqqa. Además de esta similitud formal de los muqarnas, lo más significativo es que la bóveda de Damasco arranca de una base compuesta por una galería de arcos múltiples ciegos que montan sobre pequeñas columnas. En la combinación de los arcos destacamos una secuencia de lobulado, mixtilíneo y por último, un arco polilobulado que enmarca toda la composición. En el iwan sur de Raqqa, las trompas de muqarnas apoyan también en una galería ciega conformada por dos arcos apuntados y el inferior trilobulado. La comparación establecida entre ambos ejemplos, nos sugiere que fueron realizados en el mismo momento, siglo XII [9 y 10].

Por todo lo expuesto, no podemos considerar esta portada de Raqqa como la portada con muqarnas más antigua conservada. Las referencias sobre esta cuestión son muy escasas y que no se ha investigado lo suficiente, sin embargo la presencia de esta decoración de muqarnas confirma las intervenciones posteriores que se hicieron en la que fue capital de Hārūn ar-Rashīd ${ }^{49}$.

Colloque...op. cit. p. 142.

47 MARÇAIS, G., L'Architecture musulmane d'Occident. Tunisie, Algérie, Maroc, Espagne, Sicile. Paris, Arts et Métiers Graphiques, 1954, p. 102. BURCKHARDT, T., El arte del Islam. Lenguaje y Significado. Barcelona, Sophia Perennis, 1999, p. 68: "(...) El ejemplo más antiguo que hasta ahora se conoce se descubrió en Raqqa (Siria) y data de finales del siglo VIII [a propósito del origen de los muqarnas]" y STIERLIN, H., El Islam desde Bagdad hasta Córdoba. Las edificaciones de los siglos VII al XIII. Köln, Taschen, 1997, p. 218: “(...) La técnica llamada de las estalactitas, o mukarnas, probablemente desarrollada en Persia, aunque tiene un precedente en el palacio de Harun al-Rashid en Raqqa".

48 OTTO-DORN, K.., El Islam. Barcelona, 1965, p. 89.

49 Esta cuestión ha sido tímidamente apuntada en una compilación de estudios sobre Siria y la zona de la Jazira, véase el capítulo: HILLENBRAND, R., “Eastern Islamic influences in Syria: Raqqa and Qal'at Ja'bar in the later 12th century", en RABY, J. (ed.), The art of Syria and Jazira: 1100-1250. Oxford, University Press, 1985, págs. 21-45. 


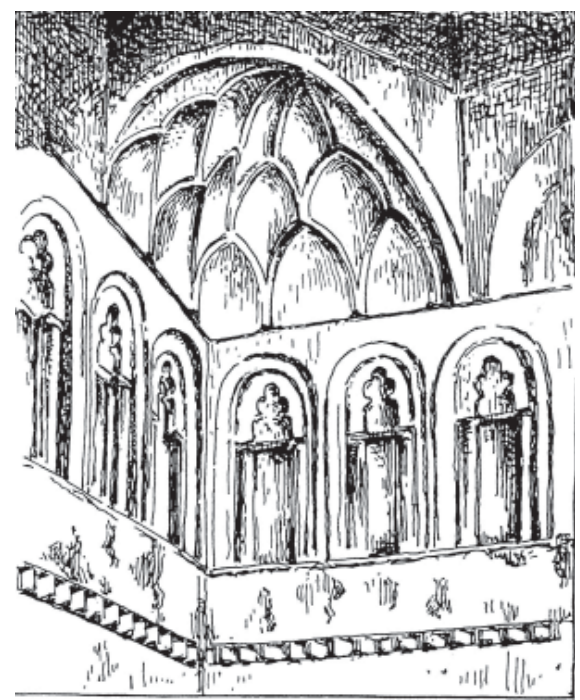

9. Kașr al-Banāt en Raqqa -Siria- (¿siglo VIII?): dibujo del iwan sur según Sarre $y$ Herzfeld. (MARCAIS, G., L'Architecture musulmane d'Occident. Tunisie, Algérie, Maroc, Espagne, Sicile. Paris, Arts et Métiers Graphiques, 1954, p. 102).

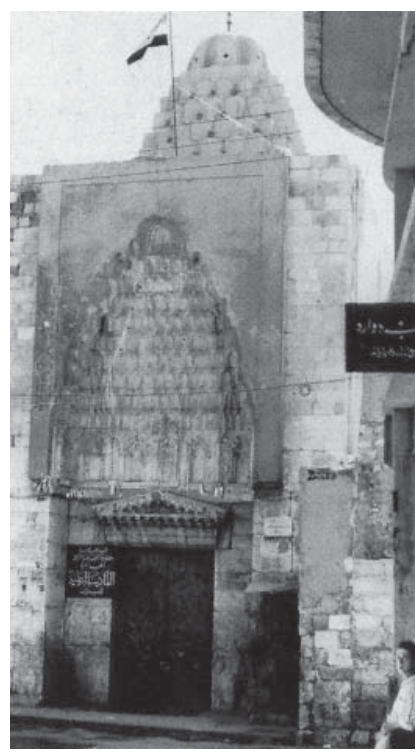

10. Exterior del Maristán Nuri en Damasco -Siria- (548/1154). (ETTINGHAUSEN,R.; GRABAR, O., Arte y Arquitectura del Islam. 6501250. Madrid, Cátedra, 2000, p. 344).

2.2. ReVisión de la problemática acerca del origen geográfico de los muqarnas: Bagdad, capital del Califato 'abbāssí, como creadora de este nuevo SISTEMA ORNAMENTAL Y SU INFLUENCIA HACIA EL RESTO DE LA GEOGRAFÍA ISLÁMICA.

La teoría que defiende el nordeste de Irán no parece convencer a muchos historiadores pues no aclara la sucesión entre las trompas de Tim o de Isfahán y las cúpulas iraquíes y sirias compuestas enteramente por celdas de muqarnas. Lo que está claro es que en algún punto se ha perdido el nexo de unión entre las manifestaciones del Irán pre- silŷuquí y silŷuquí, y lo que posteriormente serán las grandes representaciones îljāníes y timuríes que emplean los muqarnas con una soltura técnica asombrosa, configurándose nuevas tipologías de celdas y formando parte no sólo de las cúpulas sino también de los portales de entrada. Sorprende enormemente la conservación de un edificio como es la Tumba del Imān al-Dāwr en Samarra, fechado en el año 477/1085, en el que la cúpula se resuelve por medio de muqarnas, cuyas celdas se traducen también al exterior [11]. Este tipo de cubierta será habitual solamente en Iraq y en la arquitectura zengida de Siria, siendo precisamente 
la Tumba del Imān al-Dawr uno de los primeros ejemplos ${ }^{50}$. Cronológicamente, este ejemplo está muy próximo a las trompas silŷuquíes empleadas en la Mezquita de Isfahán que ya hemos visto, y sin embargo, no guardan ningún tipo de similitud formal pues en el edificio iraquí la fórmula de los muqarnas aparece perfectamente desarrollada y se usa con exquisito virtuosismo.

En la arquitectura silŷuquí se observa el empleo de muqarnas, de dos maneras distintas. En la zona de transición a través de las trompas de muqarnas, continuando con la tradición del nordeste de Irán y en estratos decorando alminares o en las cornisas Gumbad i-'Alī en Abarquh (Irán) 447/1056 y Alminar Kalan en Bujara (Uzbekistán) 520/1127-. Ahora bien, en la arquitectura de los Silŷuquíes del Rum desarrollada en Turquía y centrada en la península

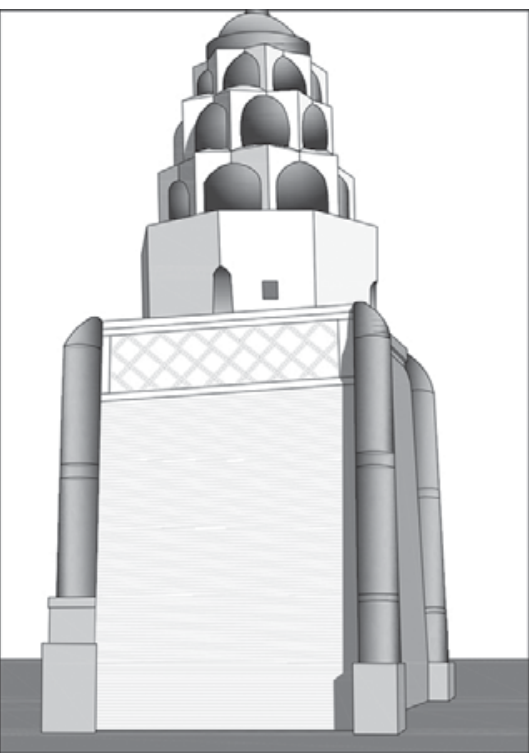

11. Dibujo del Mausoleo del Imām alDawr en Samarra-Iraq- (477/1085). de Anatolia a partir del año 469/1077, se utiliza la fórmula de los muqarnas no sólo para las cornisas o las trompas de las cúpulas sino fundamentalmente, para cubrir los portales de entrada [12, 13 y 14].

Este uso tan distinto o variado respecto de la arquitectura silŷuquí iraní conduce a que irremediablemente, haya que buscar un foco en el que se emplearan los muqarnas más allá de la trompa de esquina y que su configuración fuese mucho más compleja que simples nichos cóncavos apuntados. Un foco que permitiese la influencia en el uso absolutamente ornamental de esta fórmula en Turquía, Siria, el Norte de África y Egipto, y desde luego, las trompas iraníes conservadas no aportan nada a este desarrollo de los muqarnas. Es precisamente, la existencia del mausoleo del Imān al-Dawr, el punto de arranque de una alternativa a la historiografía tradicional basada en el hecho de que los muqarnas debieron idearse y utilizarse por primera vez en Iraq. No obstante, en la historiografía tradicional ya se apuntó esta posibilidad ${ }^{51}$, aunque sin profundizar mucho en el tema pues no hay que olvidar que con la invasión de los Mongoles y sobre todo, tras la toma de Bagdad en el año 655/1258, momento en el que la ciudad quedó prácticamente arrasada en su totalidad, muchos edificios con muqarnas debieron perderse aunque eso sí, el recuerdo hubo de quedar en la mente de sus destructores.

50 PETERSEN, A., Dictionary of islamic architecture. London, Routledge, 1996, p. 206.

51 BEHRENS-ABOUSEIF, Encyclopedie de L'Islam...op. cit. p. 505. Igualmente, Herzfeld considera Iraq como foco creador de las cúpulas de muqarnas. 


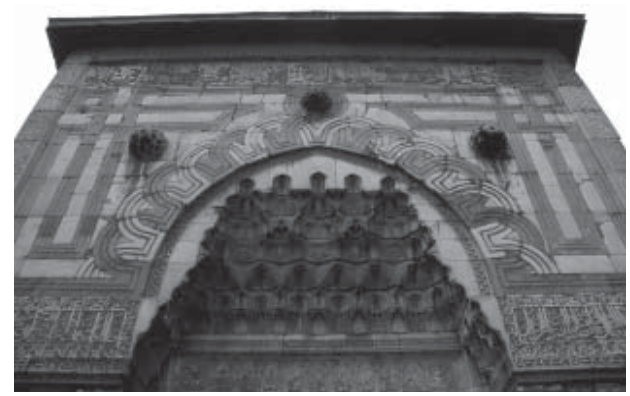

12. Madrasa Qaratay de Konya -Turquía- (648/1251): pórtico de entrada. (Fotografía de la autora, octubre'2005)

13. Madrasa Qaratay de Konya -Turquía- (648/1251): dibujo de los muqarnas del pórtico de entrada.

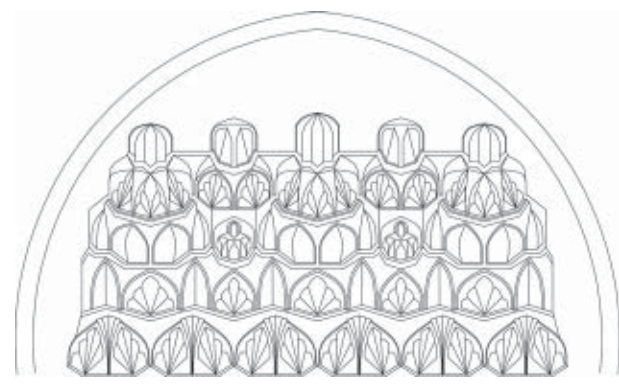

Sin embargo, no creemos que el ejemplo de la Tumba del Imān al-Dawr fuese pionero en este tipo de bóvedas de muqarnas ya que se localiza en una pequeña población, ubicada a 20 kilómetros de Samarra, y no en una ciudad, teniendo en cuenta que era en las ciudades donde se producían los avances y las innovaciones a todos los niveles. Es más que probable que el origen de este tipo de cubiertas se localizase en la capital 'abbāssí, Bagdad, máxime teniendo en cuenta que el promotor de esta obra, Muslim ibn Kuraysh, mantuvo relaciones cordiales con el Califato 'Abbāssí52. En la misma línea, hay que destacar el hecho de que no se conserven otras cúpulas de este tipo en Bagdad fechadas en el siglo XI, y sin embargo, gracias al estudio que Yasser alTabba hizo sobre miniaturas fechadas en los siglos XV y XVI, se puede comprobar que la capital 'abbāssí contaba entre su patrimonio arquitectónico con cúpulas que siguen esa disposición cónica de muqarnas ${ }^{53}$, amén de otras construcciones conservadas en Bagdad como la Tumba de Sitt Zubaydah o de Zumurrud Khatun del siglo XII o la Tumba de al-Shaykh 'Umar al-Suharawardī del siglo XIV y en otras localidades tales como, el Mausoleo de al-Hasan al-Bașrī en la ciudad de Basora fechado en la primera mitad del siglo XIII o el Mausoleo de Dhū'l-Kifl en al-Kifl del siglo XIV. Finalmente,

52 AL-TABBA, op. cit. p. 63.

53 Ibidem. Las miniaturas que muestra el autor para apoyar su tesis, datan de 1468 una y la otra de 1537, las cuales muestran vistas de Bagdad donde se pueden apreciar edificios con este tipo de cúpulas. 
los descubrimientos arqueológicos llevados a cabo en el antiguo palacio califal de Bagdad, han sacado a la luz fragmentos de bóvedas con unos elementos que estarían dispuestos en esa zona de transición. Estas estructuras halladas en Bagdad presentan la misma forma de nicho cóncavo apuntado como los ejemplos hallados en Nishapur e igualmente, sus superficies cerámicas están decoradas con relieves esgrafiados y que se han fechado hacia el siglo $X^{54}$.

Por todo lo expuesto anteriormente, debemos tener en cuenta varios aspectos que ponen de manifiesto que fue en Bagdad donde aparecieron por primera vez los muqarnas. En primer lugar, es muy significativa la utilización de arcos apuntados -derivados del arco aquillado persa- y nichos poligonales en la capital 'abbāssí ${ }^{55}$, los cuales se pueden considerar como la base formal y estilística de las primeras manifestaciones de muqarnas. La presencia de este tipo de arcos o de nichos en Bagdad, enlaza además con

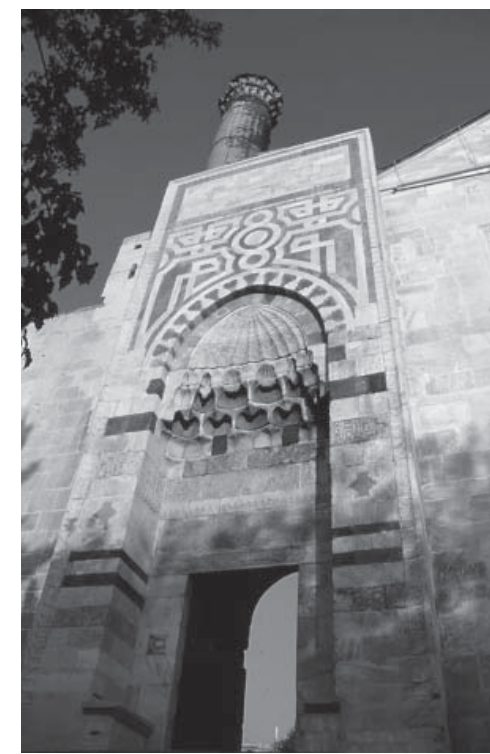

14. Pórtico de entrada de la Mezquita de Isa Bey Mosque en Selçuk -Turquía(775/1374-776/1375). el ambiente artístico pre-islámico de esta zona como fue el arte sasánida, cuya principal manifestación, el Palacio de Ctesifonte, se encuentra muy próximo a la capital. Si se acepta que el surgimiento de las celdas de muqarnas pudo tener un significado más allá del mero valor estético, en función de la propia simbología de la geometría o de cualquier teoría filosófica-teológica ${ }^{56}$, es lógico suponer que las primeras manifestaciones se llevaran a cabo en la capital del Califato donde se reunían los principales grupos filosóficos y científicos.

Pensamos que en un momento determinado del siglo VIII o IX en la propia Bagdad y partiendo del arco aquillado persa, surgió la idea de compartimentar las trompas en la zona de transición con el fin de generar un espacio más dinámico y decorativo. Al respecto, es interesante destacar cómo en el palacio de Ujaydir, fechado hacia el año 158/776 se observa en la imposta de una bóveda, un primitivo intento por enfatizar la zona de transición al disponer varios arcos apuntados concéntricos cuyo aspecto nos recuerda irremediablemente al de los primeros nichos cóncavos que constituyen la decoración primitiva de muqarnas y que deriva inequívocamente

54 PIJOÁN, J., Historia General del Arte. SUMMA ARTIS. Tomo XII: "Arte islámico". Madrid, Espasa-Calpe. S.A, 1966, págs. 156-158.

55 OTTO-DORN, op. cit. A propósito de las puertas de la Bagdad 'abbāsí del siglo VIII.

56 CARRILLO CALDERERO, A., "Las cúpulas de muqarnas: consideraciones generales acerca de su simbología”, Imafronte, Vol. 17, Murcia, 2006, págs. 7-21. 
de la trompa sasánida. Entendemos que si en Ujaydir se intentó fragmentar la trompa de esquina con el objetivo de configurar un espacio con entrantes y salientes, en la recién fundada Bagdad debió suceder lo mismo. Así, pensamos que desde aquí, la idea se propagó a otras regiones y llegó a localidades como Bujara, debido a los contactos que las dinastías gobernantes semi-independientes como los Sāmāníes, mantuvieron con la capital 'abbāssís7. No obstante, no hay que descartar la idea de que en el nordeste de Irán surgiera la composición de trompa fragmentada en nichos que posteriormente se denominaron muqarnas y que en Iraq, surgiera la idea de extraerlos de la arquitectura para constituir lo que se viene denominando como celdas de muqarnas. Es probable que a partir del siglo XI, en Bagdad surgiera la idea de reducir esos nichos de las trompas a celdas independientes, los muqarnas, con los que cubrir la zona de transición -como por ejemplo los estucos de Nishapur- o toda la cúpula -Tumba del Imān al-Dawr-.

De lo que no cabe duda es de que esta novedad tan decorativa, debió resultar muy atractiva y pronto se extendió hacia otros puntos, donde se emplearon en las trompas, cúpulas o en cornisas. A la llegada de los Silŷuquíes en el siglo XI, es probable que en el nordeste iraní la nueva fórmula se hubiese estancado en su primer escalón, es decir, solo en las trompas de esquina, lo que influyó en las cúpulas de la Mezquita de Isfahán pero debieron conocer edificios en los que las celdas de muqarnas apareciesen constituidas con independencia de las cúpulas, lo que les llevó a emplearlos en otras superficies arquitectónicas como por ejemplo las cornisas. Lo mismo debió suceder con los llamados Silŷuquíes del Rum que se establecieron en la península de Anatolia, actual Turquía, pues hasta allí llevaron una técnica de muqarnas basada en pequeñas celdas que se yuxtaponen y cubren portales de entrada.

El planteamiento de un traslado de la idea de los muqarnas desde Iraq hacia otras regiones a través de peregrinos, mercaderes, artistas o científicos es perfectamente lícito y explicaría la similitud entre las cúpulas como la del Imān al-Dawr en Iraq y las erigidas por Nūr al-Dīn en Damasco a partir del siglo XII. En la misma línea, esta idea ornamental llegaría hasta el propio Egipto, en sus dos vertientes, en forma de trompas o como celdas para decorar cornisas, ventanas o una cúpula y hasta el Norte de África, documentándose en la Ḳal'a de los Banū Ḥammād la primera manifestación del Islam occidental. Por ello, las teorías que propusieron en su momento un origen paralelo de los muqarnas en la Kal'a y en Egipto, no pueden aceptarse pues probablemente sí tuvieron un referente en la propia Bagdad aunque no se conserve ninguna manifestación fechada en ese momento, tan sólo la Tumba del Imān al-Dawr de Samarra. La influencia de Bagdad también se dejó sentir en la zona de la Ŷazīra -Jazira- donde a partir del siglo XIII, la estructura de la cúpula cónica del Imān al-Dawr se versiona en cubiertas piramidales con tejas vidriadas en el exterior y una sucesión de celdas de muqarnas en el interior, como por ejemplo en la Tumba de Awn al-Dīn en Mosul (646/1249).

57 Bosworth, C.E., The islamic dynasties. Edinburgh, University Press, 1967. En el año 875 Nasr ibn Ahmad recibió del Califa al-Mu’tamid el control sobre toda la Transoxiana y el Khurasán. 
Por tanto, entendemos que el origen fue único y los desarrollos independientes, y a pesar de ser la misma fórmula, los muqarnas orientales desarrollados por los İljāníes, Timuríes u Otomanos difieren sensiblemente de los realizados por los Almorávides, Almohades o Nazaríes de Granada en el Islam occidental.

3. EL ARTE de LOS SASÁNIDAS: REFERENTE ESTÉtICO EN LA CREACIÓN FORMAL DE LOS MUQARNAS.

Al principio de este estudio nos planteábamos dos interrogantes dónde y por qué surgen los muqarnas por primera vez. El estudio de lo que se ha investigado hasta ahora acerca del lugar en el que surgió esa renovación estética por primera vez, concluye con un foco geográfico de primera categoría como fue Bagdad, la capital del Califato 'abbāsí, y también que el origen formal de los muqarnas debemos buscarlo en la fragmentación de la trompa de esquina. Llegados a este punto, nos planteamos por qué surge ese intento por decorar la trompa de ángulo o lo que es los mismo, qué circunstancia motivó el enriquecimiento de este elemento arquitectónico.

En este sentido, ya hemos indicado la importancia del arco aquillado y de las fachadas concebidas con entrantes y salientes, creando interesantes juegos de luces y sombras. Unos elementos o condicionantes estéticos que tienen importancia fundamentalmente durante el período del Califato 'abbāsí cuando la capital se traslada de Damasco hacia Bagdad, y el arte islámico contacta más con el sustrato artístico pre-islámico de la zona. Este contexto artístico precedente se basaba en la tradición artística que en su suelo habían dejado las dinastías de los Aqueménidas, Partos y Sasánidas, caracterizada por una arquitectura espacialmente seccionada y abovedada, por la fragmentación espacial de los muros y por el uso del estuco o decoración esculpida en piedra, donde se aprecia el gusto por la repetición de motivos decorativos. Si la arquitectura de los Aqueménidas se caracteriza por el empleo de estructuras adinteladas, será la conciencia fuertemente irania lo que llevó a los Partos ${ }^{58}$, a crear un arte basado en la tradición oriental y autóctona de la región libre de cualquier intrusión artística procedente de la cultura mediterránea. Esta tendencia artística basada en los parámetros orientales iranios continuó con los Sasánidas ${ }^{59}$, como ponen de manifiesto los restos arqueológicos que han llegado hasta la actualidad y que fueron, sin duda alguna, los que tanto impresionaron a los conquistadores islámicos.

El mejor ejemplo para ilustrar esta idea es el Palacio de Ctesifonte fechado en la segunda mitad del siglo III d.J.C. y construido por Sapor I60, cuyos restos debieron maravillar a aquellos conquistadores que bajo el estandarte del Islam conquistaron el antiguo territorio persa y cuyas formas arquitectónicas influyeron muy directamente en la arquitectura 'abbāsí, teniendo en cuenta la proximidad geográfica de Ctesifonte

58 GHIRSHMAN, R., Irán: Partos y Sasánidas. 1962, El Universo de las Formas, Aguilar, S.A., págs. 15-17. 59 GHIRSHMAN, R., Persia y la afirmación de su arte. Barcelona, El Arte y el Hombre. Vol. I. Planeta S.A., 1965. p. 390.

60 GHIRSHMAN, Irán: Partos y Sasánidas... op. cit. p. 136. 


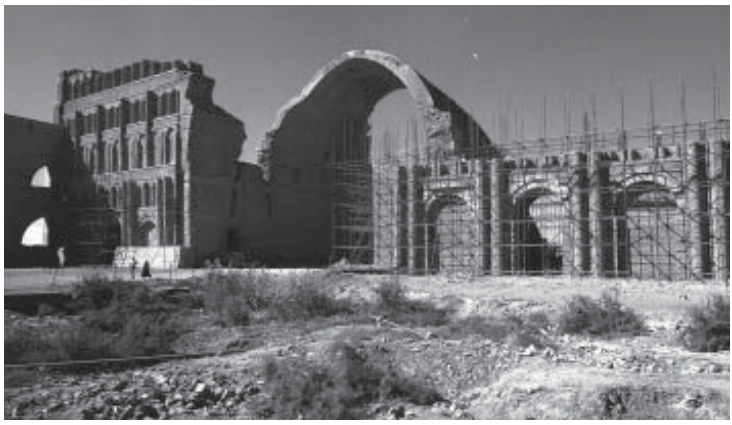

15. Palacio de Ctesifonte -Iraq-(sigloIIId.J.C.). (AA.VV. El Islam. Arte y Arquitectura, Könemann, 2001, p. 33).

respecto de Bagdad. La fachada de este palacio está presidida por un gran iwan, se erige en sentido longitudinal y presenta una rica decoración dispuesta en cuatro pisos, fragmentada por nichos ciegos flanqueados por columnas [15]. La sala conservada en el interior del palacio de Ctesifonte, es de planta cruciforme y está compuesta por un espacio cuadrangular central, flanqueado en sus cuatro frentes por iwanes, y decorada por nichos ornamentados con grecas y elementos vegetales ${ }^{61}$. Pues bien, esta tipología de planta utilizada en los palacios sasánidas y a su vez tomada de la arquitectura parta, que divide el espacio en diferentes salas cubiertas por cúpulas sobre trompas y con la constante presencia del iwan ${ }^{62}$, fueron tomadas por la arquitectura islámica que supo adaptarlas a sus necesidades civiles o litúrgicas, empleándolas no sólo en palacios sino también en mezquitas como se puede comprobar en la arquitectura silŷuquí.

Entendemos que del mismo modo que el iwan pasó a formar parte del vocabulario de la arquitectura 'abbāsí, el gusto sasánida por articular los muros en entrantes y salientes supuso un detonante muy importante en la mente de los constructores musulmanes del Califato 'abbāsí, el cual se tradujo en una compartimentación de las superficies arquitectónicas. Esta tendencia se revela ya en los ejemplos 'abbāsíes más tempranos como el Palacio de Ujaydir [16], que ya hemos mencionado y en el que por un lado, podemos observar cómo las fachadas se articulan por medio de entrantes y salientes que le confieren un aspecto externo muy diferente del que presentan las edificaciones omeyas y por otro, la utilización de una trompa de esquina compartimentada por medio de pequeños arcos concéntricos a la manera de "las trompas sasánidas".

El aspecto formal de los muqarnas responde a un cuarto de esfera cóncavo y por qué no decirlo, a un iwan arquitectónico de pequeño tamaño. Su empleo primitivo

61 GHIRSHMAN, Persia y la afirmación de su arte...op. cit. p. 396 y 397.

62 A propósito del estudio de los palacios sasánidas, son muy interesantes los siguientes estudios: GRABAR, O., "Sarvistan: a note on Sasanian palaces" que forma parte de una recopilación de artículos diversos de Oleg Grabar y recogidos en el libro Early Islamic Art, 650-1100. Vol. 1 Constructing the study of Islamic Art, publicado en Hampshire por Ashgate Publishing Limited en el año 2005, aunque el studio citado se publicó por primera vez en Estambul en 1970; y también, BIER, L., "The Sasanian palaces and their influence in early Islam", en ARS ORIENTALIS, VOL. 23, University of Michigan, 1993. 
en la zona de transición y su posterior desarrollo como celdas independientes, debió responder a una continuidad del arte 'abbāsí con la estética sasánida de luces y sombras, de entrantes y salientes. En este sentido, es interesante señalar cómo en época sasánida se fabricaron copas de vidrio decoradas con motivos de panales de abejas $^{63}$, cuyo convexo aspecto enfatiza el interés por superficies movidas y ondulantes de los Sasánidas y que defendemos, influyó notablemente en la concepción arquitectónica y estética 'abbāsí.

En definitiva, formas que fragmentasen las líneas arquitectónicas y si bien debieron emplearse primeramente en Bagdad y en sus alrededores, pronto pasó al nordeste de Irán donde aún imperaba el espíritu persa caso de Nishapur, Balj, Merv o Bujara. Estas ciudades del nordeste iraní crearon una cultura del Islam

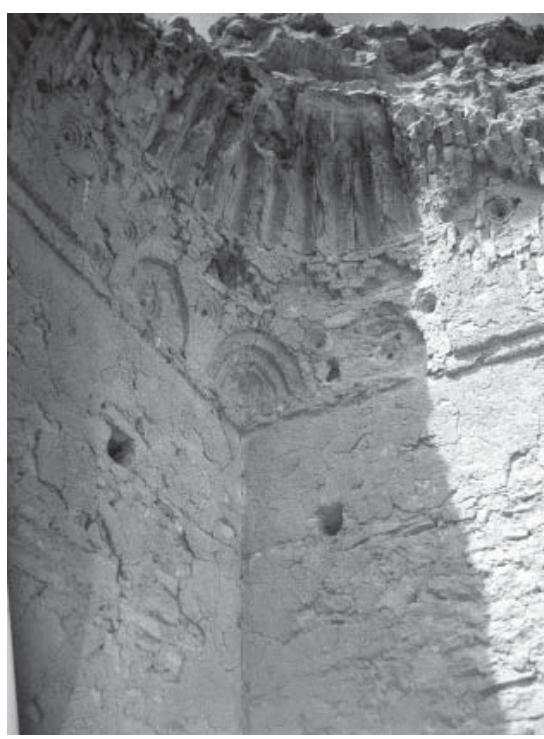

16. Detalle de la imposta de una bóveda en el Palacio de Ujaydir-Iraq- (siglo VIII). (GABRIELI, F., [et al.]. Iraq en los siglos VIII-XIII: el apogeo de la cultura arábigomusulmana. Madrid, Encuentro, 1998, p. 51). completa y definitiva hacia el siglo $\mathrm{X}$, alcanzando en ese momento lo que los autores han venido a considerar como el "Renacimiento iraní" 64 . Una cultura en cualquier caso, íntimamente emparentada con su pasado pre-islámico, con el arte sasánida y cuyo enriquecimiento en el siglo $X$ entendemos se debió a una derivación o contaminación de las innovaciones arquitectónicas y recursos ornamentales que se habían o estaban empleando en las grandes capitales del imperio 'abbāsí, Bagdad y Samarra.

63 GHIRSHMAN, Irán: Partos y Sasánidas....op. cit. Del mismo modo, ese interés sasánida por el juego de luces y sombras creado por la presencia de nichos ciegos, se puede apreciar no sólo en su arquitectura sino también en las artes suntuarias, destacando en este sentido la producción de copas de vidrio decoradas con motivos de panales de abejas.

64 GRABAR, La formación del...op. cit. p. 49 y 50. 